\title{
Perceived Organization Support Role in Creating an Innovative Work Behavior
}

\author{
Muhammad Sulaiman, Mohamed A. Ragheb, Mohamed Wahba \\ The Arab Academy for Science and Technology \& Maritime Transport, Alexandria, Egypt \\ Email: meanoow@hotmail.com
}

How to cite this paper: Sulaiman, M., Ragheb, M.A. and Wahba, M. (2019) Perceived Organization Support Role in Creating an Innovative Work Behavior. Open Access Library Journal, 6: e5372. https://doi.org/10.4236/oalib.1105372

Received: April 3, 2019

Accepted: May 24, 2019

Published: May 27, 2019

Copyright $\odot 2019$ by author(s) and Open Access Library Inc.

This work is licensed under the Creative Commons Attribution International License (CC BY 4.0).

http://creativecommons.org/licenses/by/4.0/

(c) (i) Open Access

\begin{abstract}
A research gap was found in evaluating the role of Innovative Work Behavior in the food and Beverage sector, which is important for organizations to gain a competitive advantage. Therefore, this research aims to test the impact of the Perceived Organization Support and on the Employees Innovative Work Behavior in the Food and Beverage Sector in Egypt. It also aims to test the mediation role of Learning Organizations and Work Engagement between each of Perceived Organization Support and Employees Innovative Work Behavior. Thus, a semi-structured interview will be constructed with managers of Food and Beverage SMEs to explore the dimensions affecting Innovative Work Behavior. Also, a questionnaire will be constructed with the employees of the same SMEs to test the relationships under study. Regression analysis and structural equation modeling will be used to respond to the research hypotheses.
\end{abstract}

\section{Subject Areas}

Management Organization

\section{Keywords}

Perceived Organization Support, Innovative Work Behavior, Work Engagement, Food and Beverage SMEs

\section{Introduction}

Innovative Work Behavior had been proved to be important for the purpose of organizations success. An evidence was introduced that employees innovative work behavior (IWB) has a highly important role which helps organizations to gain competitive advantage. A focus on the factors that improve IWB was done; on the other hand, few studies have investigated the negative aspects of it and 
how to buffer such conflict [1]. Nowadays, knowledge-driven economy, maximizing the innovative potentials of employees has become a top priority in every organization. Employees offer organizations a competitive advantage through differentiation and enhancement of products or services by generating new ideas and initiatives. Employees were encouraged to be engaged in innovative behavior through effective interventions provided by researchers and practitioners in human resource development (HRD), with the growing significance of intellectual capital across all business sectors [2].

Furthermore, it was expected that HRD plays a more critical role in facilitating a culture that supports innovation than ever before, considering that innovation requires a cultural change with collaboration. Given the existing emphasis on innovation in HRD, however, research on determinants that motivate employees' innovative behavior is still incomplete [2]. The intentional introduction of new and useful ideas, in addition to a set of behaviors needed to develop, launch and implement ideas with an aim to improve personal and/or business performance is referred to by IWB. Employee's attempt to find ultimate meaning and purpose in his/her work and strengthen his/her interconnectedness is referred to by workplace spirituality. It was suggested that workplace spirituality, when nurtured with perceptions of organizational support, fosters employee's creativity [3].

\section{Literature Review}

This section will introduce the definition of Innovative work behavior according to previous contributions and studies, and the relations between Innovative work behavior with learning organization and perceived organizational support moderated by work engagement.

\subsection{Innovative Work Behavior Concept and Meaning}

Innovative work behavior was defined as "intentional creation, introduction and application of new ideas within a work role, group or organization, in order to benefit role performance, the group, or the organization". Then this definition is limited to the creation, promotion, and implementation of new ideas that benefit organizations. This innovative work behavior can be in the form of the implementation of new methods, new procedures, or new approaches in an organization that are valuable to the organization. For example, in at an international media company one of the mangers created a new method to encourage innovation by establishing "rebel camps" for training other managers to be innovators, which give benefit to the company. So, according to this definition employees are encouraged to extra tasks more than team, group, or organization routines [1].

The respond to rapid change might be not applicable through the routines implemented by teams or organizations. Then, employees need to develop, endorse, and implement new methods, approaches or procedures. The definition 
also includes taking risks. The effects of new ideas knowledge are not well known to innovative employees. In other words, this innovation may put employee's status and rewards in the organization at risk. At the end, a truly new idea or combination of existing ideas may create innovation. Creation, promotion and implementation of ideas are the three steps of the complex process called IWB. The problem that needs a solution is then the initiative of innovation process which motivates employee creation of new ideas. After creation an individual have to market the idea to gain support for their implementation as real products, services, methods, or techniques. The organization can benefit from supporting these new ideas at the end. Also, innovative employees might gain more job satisfaction, get better performance in the workplace, develop better relationships with other colleagues, experience relatively low stress, enjoy higher personal growth and produce positive conflicts [1].

Individual innovative behavior was also defined as an individual intentional behavior introduce and/or apply new ideas, products, processes and procedures to his or her work role, unit or organization. Based on this definition, new ideas, products, processes and procedures are considered both in their introduction and implementation, as they pertain to innovative behavior. Moreover, the word 'New' the previous statement does not necessarily refer to new idea to the field but it may refer to relatively new to the unit or initiating new technology which has not been used in the organization before. In addition, innovative behavior includes both technical and administrative innovation. Introducing and/or applying of new technologies, products and services is referred to as technical innovation, while introducing and/or applying of new procedures and policies is considered administrative innovations [4].

Employee innovation behavior EIB is an expression referring to of the inner creativity of employees; it is a method to innovate creative products and processes through employees which generate and implement new ideas to improve performance or solve work-related problems. Introducing all individual behaviors which guide to the generation, introduction and application of beneficial novelty at various levels is included in EIB. It is highly related to employee creativity, which must result in final outputs and produce actual benefits to the organization. Creativity reflects the initial stage in a multiple stage process called [5].

New ideas are generated by the employee after recognizing the problem, then mobilizing support from others for applying the new idea. Later on, the idea is now ready for implementation and come to reality by producing a new prototype or model. Various behaviors formulate a single stage of the process in which altogether may get new process, product, market or organizational structure. Employees' intentional introduction of new products/services or new ways of doing things through the process of idea generation and implementation refer to EIB. In services, EIB may be influenced by various job characteristics and it is also considered as workplace behaviors; thus, they unavoidably relate to job characteristics, which have been found to affect the behaviors of employees di- 
rectly or indirectly through psychological states [5].

\subsection{The Relationship between Social Support and Innovative Work Behavior}

Tangible and intangible outcomes from employee experiences develop perceptions of organizational support through the daily exchange process with the organization. When positive outcomes come from these exchanges employee's extra-role activities are also triggered. It was also proposed that inclination toward initiating creative ideas, exploring possible opportunities, solving current and future problems and translating their creative inputs into actions and innovative output increase when employees recognize that the organization shows concern, offers nonjudgmental, honest feedback about their work and supports their actions. IWB is not one-time discrete activity and it seems to be continuous process as employees generate new ideas and, in parallel way they are busy in implementing these ideas by building organizational support and others' ideas by being a part of the overall team that has to implement the ideas [3].

Social support types including Perceived Organizational Support (POS), Perceived Supervisor Support (PSS), and Perceived Coworker Support (PCS). Social support is part of the job resources; it refers to the extent to which organizations and supervisors' value the contribution and well-being of their employees [6]. and coworkers' willingness to help each other complete work-related tasks [7].

Employees need strong perceptions of management and supervisor support to display IWBs, in by giving them freedom at work and resource availability, collective role behaviors at work to share ideas and build support and individual role behaviors clarifying personal loyalty, flexibility, risk taking and fearlessness. It is then expected that perceived organizational support POS encompasses certain psychological characteristics which may motivate IWB of employees. Increase behaviors that support organizational goals, and IWB is one of such positive behaviors, is a result of feelings of obligation which come from the perceptions of the social exchange framework that underlies POS. Thus, this obligation feeling result that POS would drive extra-role behavior such as IWB. It was finally concluded that employees perceived organizational support POS positively influences innovative work behavior IWB [3].

\subsection{Mediating Role of Learning Organization between Social Support and Innovative Work Behavior}

Nowadays, maximizing the innovative potentials of employees has become a top priority in every organization. Employees generate new ideas and initiatives offering the organizations a competitive advantage through differentiation and enhancement of products or services. Employees are encouraged to engage in innovative behavior, with the growing significance of intellectual capital across all business sectors, researchers and practitioners in human resource development (HRD) can thus be expected to develop and provide effective interventions. Furthermore, it is now expected that that HRD plays a more critical role in 
facilitating a culture that supports innovation than ever before, considering that innovation requires a cultural change with collaboration. However, research on determinants that stimulate employees' innovative behavior is still incomplete, given the current emphasis on innovation in HRD [2].

Problem-solving skills or motivation and organizational factors including leadership and work group relations influence innovative behavior. It is considered an important factor when organizational culture motivates innovation because innovation goes beyond individual-level idea generation. An attempt was found to examine the effect of organizational climate on innovative behavior. It was found that innovative behavior is motivated by organizational justice through the psychological mechanism of perceived organizational support. It was also stated that individual innovative behavior is affected by role expectations and leader-member exchange. Moreover, innovative behavior is predicted by transformational leadership and this relationship is mediated by psychological empowerment. Employees' innovative behaviors sources was explored and stated as organizational learning capabilities and knowledge sharing (another innovative effort), because knowledge dissemination serves as initial idea generation [2].

Motivating organizational culture that values continuous learning, knowledge sharing, employee empowerment, and social interactions among its members altogether enhance employees' innovative behaviors seems important. An important component of innovation is employee intrinsic motivation and positive emotions that elicit a deeper engagement with the innovation process. The role of intrinsic motivation was emphasized in the innovation process by identifying three dimensions of creativity: motivation, knowledge, and skills. It was also stated that intrinsic motivation helps employees become flexible, persistent, and goal-oriented. It was also highlighted that motivation is linked to innovation and that people who are highly motivated are most likely to deal with obstacles they face and take a proactive attitude to their work. Individuals' work engagement promoted by intrinsic motivation is significantly related to innovation in terms of improving personal initiatives. In addition, employees devoted their time and energy to their work facilitating their creativity when they have confidence in their personal ability to achieve goals. It was also stated that individual work engagement improves personal initiative, and accordingly influences innovation [2].

Organizational innovation is also boosted by energy that engaged employees bring into their work by enabling them to be more proactive and responsible. People feel positive when they are engaged to their work which leads to creative and explorative thinking and idea implementation, which in turn increase personal resources. At the end, it is concluded that engagement seems to play a mediating role in the relationship between the learning organization and innovative behavior. There is a link between innovative behaviors and engaged employees. A framework that aligns engagement with the organization's leadership, learning, and support system is necessary when employees' innovative behaviors are 
to be systematically motivated and developed within an organization [2].

\subsection{Mediating Role of Work Engagement between Social Support and Innovative Work Behavior}

Work engagement is a persistent, positive, affective-motivational state of fulfilment in employees that is characterized by energy, dedication and absorption [8]. Given its importance, an increasing number of studies examined factors that affect work engagement (e.g. [9]). Among these factors were social support types including Perceived Organizational Support (POS), Perceived Supervisor Support (PSS), and Perceived Coworker Support (PCS).

Moreover, studies that have examined the effect of the three types of social support on work engagement specifically, also recorded some non-uniformity in results. For example, in one of the studies, all the three types had significant effect, with POS having the greatest effect.

Nevertheless, a review of the literature on studies focusing on one or two types of social support confirms the positive impact of POS on work engagement (e.g. [10]. However, inconsistency of results was witnessed among PSS and PCS. Some studies have failed to prove the significant effect of PSS and/or PCS on work engagement (e.g. [11] [12]), whereas others are debatable regarding the relative importance of PSS and PCS to work engagement. Those who believe that PSS is more important consider it as a more stable resource to employees [9], while PCS advocates believe that colleagues are the heart of social support [7], and help combat health impairment symptoms [13]. From the review above, it can be concluded that the few studies including the three social support types together, as well as those that concentrated on one or two types show that POS has a relatively higher consistency in its results compared to PSS and PCS. Accordingly, this research attempts to distinguish between the effects of each type of social support through including them in one study and examining their effect on work engagement.

Besides social support, other personal resources such as psychological empowerment in spite of its importance in raising employees' work engagement have been rarely investigated [14]. Psychological empowerment (including meaning, competence, self-determination, and impact) refers to a set of psychological states that are necessary for individuals to feel a sense of control in relation to their work [15]. Unlike job resources, psychological empowerment leads to intrinsic motivation through employees' perception of empowerment. Hence, it is considered a personal belief rather than a job characteristic [16].

Additionally, empowerment theorists view psychological empowerment as an explanatory mechanism through which contextual factors affect individuals' attitudes. This can be attributed to the fact that psychological empowerment is a cognitive model that reflects people's perception toward themselves in relation to work environment based on individual differences. Consequently, it can be argued that adding psychological empowerment as a mediator could help ex- 
plain the social support effect on work engagement, and hopefully, their associated inconsistency [15].

Another point that has been raised in the work engagement literature is that the research is predominantly Western-based [17]. Explaining work engagement in different cultural contexts will add value to the established literature by comparing its results to other relatively new contexts, which will eventually help generalize the findings and broaden understanding of the engagement process. To fill this research gap, this study examines work engagement in Egypt.

Studying work engagement in Egypt is important because Egypt tends to have high propensity of disengaged employees; it alone accounted for 32 percent of disengaged employees in the Middle East region [18]. The disengagement problem in Egypt has been a crucial but under-resolved challenge. Factors such as autocratic management styles denoted by a high-power distance culture have contributed to the disengagement status for many years. In addition, with the recent economic and political unrest.

following the 2011 revolution, employees' attitudes toward their work have changed [19], their demands increased and the disengagement problem intensified, as reflected in 1969 strikes in 2012 compared to 530 in 2010 [20]. Therefore, this study focuses on examining the effect of both social support and psychological empowerment in raising Egyptians' engagement under the current tough conditions.

\section{Research Framework}

\subsection{Variables and Measurement}

The variables used in this study can be categorized into three main types which are; the dependent, independent variables and mediator variables.

\subsubsection{Dependent Variable}

The dependent variable for this study is Innovative Work Behavior.

\subsubsection{Independent Variable}

There are three independent variables that will be measured. These are state POS, PSS, IWB

\subsubsection{Mediator Variables}

There are three variables representing the mediator Learning Organization Work Engagement (Vigor, Dedication, and Absorption). The relationship between dependent variable, mediator variables and independent variables is explained in Figure 1.

In the questionnaire assigned, the questions were adopted to measure the dimensions under study by implementing a 5-point Likert -scale used for all responses with $(1=$ Strongly Disagree, $2=$ Disagree, $3=$ Neutral, $4=$ Agree, $5=$ Strongly Agree). Thus, the literature had been reviewed and the following hypotheses were assumed: 


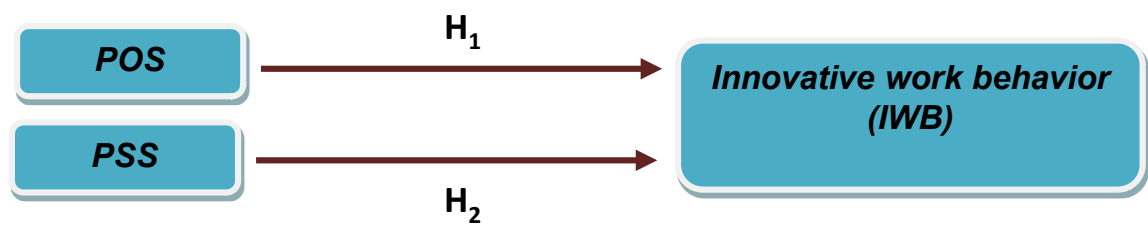

Figure 1. Research framework for the current study.

$\mathrm{H}_{1}$ : There is a significant positive impact of Perceived Organization Support on Work Behavior.

$\mathrm{H}_{2}$ : There is a significant positive impact of Perceived Supervisor Support on Work Behavior.

\section{Results and Findings}

To test the hypotheses mentioned above, the current research used regression analysis and structural equation modeling (SEM). This requires testing the validity and reliability of the research variables as well as presenting a descriptive analysis of the research variables under study. After that, the hypotheses testing will be presented through the model constructed. As a preliminary step, the frequency tables are computed for the research variables.

\subsection{Descriptive Analysis}

The descriptive statistics is a tool in which it explains and gives a distinct understanding of the features of certain data set, by giving short summaries about samples and how to measure the data. The three major types of descriptive analysis are frequency, measures the central tendency such as averages, and measure of variability such as standard deviation. Measures of variability describes the level of how different the scores are from the mean. Measures of central tendency suggest unique value that generally represents the entire scores set.

Frequency statistics sum how many times each variable is repeated; for instance, the number of employed and unemployed among the sample. In the following section, means, standard deviations and frequency statistics will be conducted on both; demographic data and the research variables. Table 1 shows the frequency tables for the research variables, where it could be observed that responses vary between strongly disagree and strongly agree, which means that not all responses are in the zone of agreement. Therefore, Perceived Organizational Support, Perceived Supervisor Support, Innovative Work Behavior need to be improved.

\subsection{Data Testing}

To test the validity of the research variables, confirmatory factor analysis was used to calculate the Average Variance Extracted (AVE) and Factor Loading (FL) of each construct. Therefore, confirmatory factor analysis using the principal component method was used to examine the convergent validity of the research dimensions. Reliability test is an assessment of the degree of consistency 
Table 1. Frequency table for research variables.

\begin{tabular}{ccccccccc}
\hline & & & & \multicolumn{5}{c}{ Frequency } \\
\cline { 5 - 9 } Variable & N & Mean & Std. Deviation & \multicolumn{1}{c}{2} & 3 & 4 & 5 \\
\hline Perceived Organizational Support & 418 & 1.5574 & 0.71490 & 230 & 151 & 31 & 4 & 2 \\
Perceived Supervisor Support & 418 & 1.6651 & 0.67343 & 180 & 204 & 30 & 2 & 2 \\
Innovative Work Behavior & 418 & 1.6579 & 0.69268 & 189 & 190 & 32 & 7 & 0 \\
\hline
\end{tabular}

between multiple measurements of a variable. Cronbach's alpha is the most widely used measurement tool with a generally agreed lower limit of 0.7 . Table 2 provides an overview of the reliability scores. As can be seen from this table, all the alpha coefficients were above the required level of 0.7. The table also shows the results of the KMO, AVE and FL for each variable and the corresponding constructs. It could be observed that the KMO and AVE values are all above 50\% and the FL are all above 0.4 except for the third item in Innovativeness in Work Behavior which was excluded in the reliability test. This indicates that the research variables have adequate convergent validity.

\subsection{Hypotheses Testing}

In this section, the researcher will present the findings of the model significance through presenting the correlation and regression analysis results. This will provide a decision whether to accept or reject the hypotheses under study.

\subsubsection{Testing the First Hypothesis: The impact of Perceived Organizational Support on Innovative Work Behavior}

This hypothesis is designed to test the impact of Perceived Organizational Support on Innovative Work Behavior. Table 3 shows the output of applying multiple regression analysis, where it was found that the Perceived Organizational Support under study explain $32.4 \%$ of the variation in Innovative Work Behavior, as R-square $=0.324$. The importance of Perceived Organizational Support according to the standardized coefficient beta is determined as follows: ( $\beta=$ 0.552 , P-value $=0.00$ ) which indicates that the variable "Perceived Organizational Support" was found to be Significant as its P-values was less than 0.05 .

\subsubsection{Testing the Second Hypothesis: The impact of Perceived Supervision Support on Innovative Work Behavior}

Table 4 shows the output of applying multiple regression analysis, where it was found that the Perceived Supervision Support under study explain 32.6\% of the variation in Innovative Work Behavior, as R-square $=0.326$. The importance of Perceived Supervision Support according to the standardized coefficient beta is determined as follows: $(\beta=0.588$, P-value $=0.00)$ which indicates that the variable 'Perceived Supervision Support' was found to be Significant as its P-values was less than 0.05 .

Table 5 shows the SEM model for the effect of Perceived Organization Support, and Perceived Supervisor Support on Innovative Work Behavior. It was 
Table 2. KMO, average variance extracted and factor loadings of items.

\begin{tabular}{|c|c|c|c|c|c|}
\hline Variables & $\mathrm{KMO}$ & AVE & $\begin{array}{c}\text { Cronbach's } \\
\text { Alpha }\end{array}$ & Items & Item Loading \\
\hline \multirow{10}{*}{ POS } & \multirow{10}{*}{0.934} & \multirow{10}{*}{$60.093 \%$} & \multirow{10}{*}{0.926} & 1 & 0.837 \\
\hline & & & & 2 & 0.800 \\
\hline & & & & 3 & 0.742 \\
\hline & & & & 4 & 0.750 \\
\hline & & & & 5 & 0.746 \\
\hline & & & & 6 & 0.751 \\
\hline & & & & 7 & 0.753 \\
\hline & & & & 8 & 0.773 \\
\hline & & & & 9 & 0.819 \\
\hline & & & & 10 & 0.775 \\
\hline \multirow{5}{*}{ PSS } & \multirow{5}{*}{0.784} & \multirow{5}{*}{$54.727 \%$} & \multirow{5}{*}{0.792} & 1 & 0.568 \\
\hline & & & & 2 & 0.547 \\
\hline & & & & 3 & 0.476 \\
\hline & & & & 4 & 0.593 \\
\hline & & & & 5 & 0.553 \\
\hline \multirow{5}{*}{ IWB } & \multirow{5}{*}{0.655} & \multirow{5}{*}{$50.772 \%$} & \multirow{5}{*}{0.748} & 1 & 0.600 \\
\hline & & & & 2 & 0.481 \\
\hline & & & & 3 & Deleted \\
\hline & & & & 4 & 0.497 \\
\hline & & & & 5 & 0.608 \\
\hline
\end{tabular}

Table 3. Regression analysis of perceived organizational support on innovative work behavior.

\begin{tabular}{|c|c|c|c|c|c|c|}
\hline \multirow{2}{*}{ Model } & \multicolumn{2}{|c|}{$\begin{array}{l}\text { Unstandardized } \\
\text { Coefficients }\end{array}$} & \multirow{2}{*}{$\begin{array}{c}\text { Standardized } \\
\text { Coefficients } \\
\text { Beta }\end{array}$} & \multirow[t]{2}{*}{$\mathrm{T}$} & \multirow{2}{*}{ Sig. } & \multirow{2}{*}{ R Square } \\
\hline & B & Std. Error & & & & \\
\hline (Constant) & 0.798 & 0.067 & & 11.92 & 0.000 & \multirow[b]{2}{*}{0.324} \\
\hline $\begin{array}{c}\text { Perceived Organizational } \\
\text { Support }\end{array}$ & 0.552 & 0.039 & 0.570 & 14.15 & 0.000 & \\
\hline
\end{tabular}

a. Dependent variable: Innovative work behavior.

Table 4. Regression analysis of perceived supervisor support on innovative work behavior.

\begin{tabular}{|c|c|c|c|c|c|c|}
\hline \multirow{2}{*}{ Model } & \multicolumn{2}{|c|}{ Unstandardized Coefficients } & \multirow{2}{*}{$\begin{array}{c}\text { Standardized } \\
\text { Coefficients } \\
\text { Beta }\end{array}$} & \multirow{2}{*}{$\mathrm{T}$} & \multirow{2}{*}{ Sig. } & \multirow{2}{*}{ R Square } \\
\hline & $\mathrm{B}$ & Std. Error & & & & \\
\hline (Constant) & 0.680 & 0.074 & & 9.14 & 0.000 & \\
\hline $\begin{array}{c}\text { Perceived } \\
\text { Supervisor Support }\end{array}$ & 0.588 & 0.041 & 0.571 & 14.19 & 0.000 & 0.326 \\
\hline
\end{tabular}

a. Dependent variable: Innovative work behavior. 
Table 5. SEM model for the effect of social support on innovative work behavior.

\begin{tabular}{cccccc}
\hline & & Estimate & P-value & R Square \\
\hline $\begin{array}{c}\text { Innovative Work } \\
\text { Behavior. }\end{array}$ & $<--$ & $\begin{array}{c}\text { Perceived Organiza- } \\
\text { tion Support }\end{array}$ & 0.373 & $* * *$ & \\
$\begin{array}{c}\text { Innovative Work } \\
\text { Behavior. }\end{array}$ & $<---$ & $\begin{array}{c}\text { Perceived Supervisor } \\
\text { Support }\end{array}$ & 0.545 & $* * *$ & 0.498 \\
\hline
\end{tabular}

Table 6. Model fit for the effect of social support on innovative work behavior.

\begin{tabular}{cccccc}
\hline CMIN/DF & p-value & GFI & CFI & AGFI & RMSEA \\
\hline 1.500 & 0.000 & 0.948 & 0.979 & 0.931 & 0.035 \\
\hline
\end{tabular}

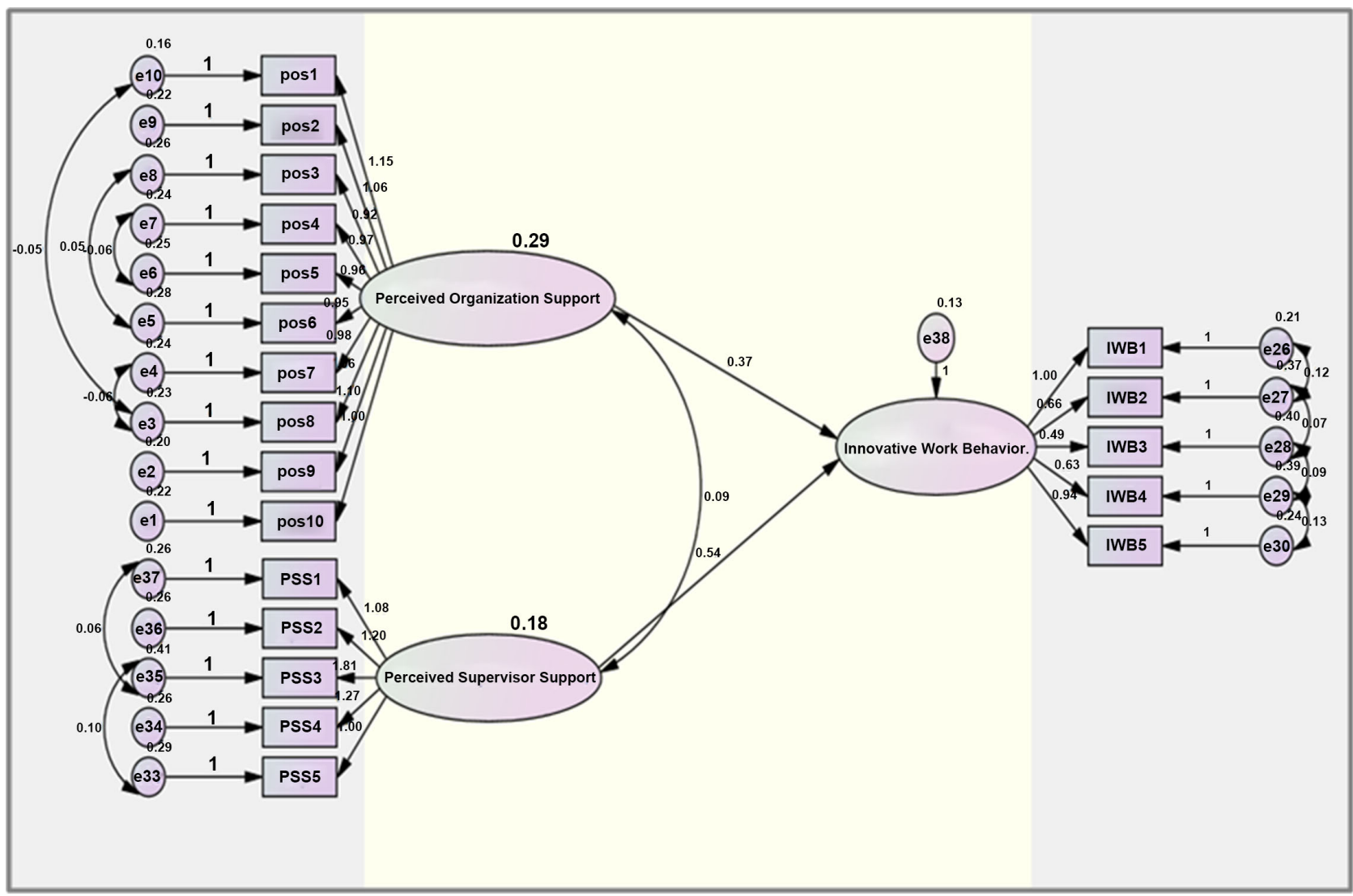

Figure 2. SEM model for the effect of social support on innovative work behavior.

observed that there is a significant effect of Perceived Organization Support, and Perceived Supervisor Support, with estimates of 0.373 , and 0.545 respectively and P-values of 0.00. Also, the R Square is 0.498 , which means that Social Support; Perceived Organization Support, and Perceived Supervisor Supportexplain $49.8 \%$ of the variation in Innovative Work Behavior.

The model fit indices shown in Table 6 are described as minimum discrepancy (CMIN), goodness of fit index (GFI), comparative fit index (CFI), incremental fit index (IFI), Tucker-Lewis index (TLI), and root mean square of approximation (RMSEA). It was found that $\mathrm{CMIN} / \mathrm{df}=1.500, \mathrm{GFI}=0.948, \mathrm{CFI}=0.979$, 
AGFI $=0.931$ and RMSEA $=0.035$ are all within their acceptable levels (Figure 2).

Thus, both the first hypothesis that there is positive impact of Perceived Organizational Support on Innovative Work Behavior and the second hypothesis that there is positive impact of Perceived Supervision Support on Innovative Work Behavior are fully supported.

\section{Discussion and Conclusion}

The statistical tests of multiple regression analysis and Structural Equation Modeling (SEM) presented above enabled the researcher to identify the social support that had the most significant positive impact on Innovative Work Behavior. The multiple regression applied showed that the constructs that had the most significant positive impact on Innovative Work Behavior could be classified as Perceived Organizational Support and Perceived Supervision.

\section{Conflicts of Interest}

The authors declare no conflicts of interest regarding the publication of this paper.

\section{References}

[1] Shih, H.A. and Susanto, E. (2011) Is Innovative Behavior Really Good for the Firm? Innovative Work Behavior, Conflict with Coworkers and Turnover Intention: Moderating Roles of Perceived Distributive Fairness. International Journal of Conflict Management, 22, 111-130. https://doi.org/10.1108/10444061111126666

[2] Park, Y.K., Song, J.H., Yoon, S.W. and Kim, J. (2014) Learning Organization and Innovative Behavior: The Mediating Effect of Work Engagement. European Journal of Training and Development, 38, 75-94. https://doi.org/10.1108/EJTD-04-2013-0040

[3] Afsar, B. and Badir, Y. (2017) Workplace Spirituality, Perceived Organizational Support and Innovative Work Behavior: The Mediating Effects of Person-Organization Fit. Journal of Workplace Learning, 29, 95-109. https://doi.org/10.1108/JWL-11-2015-0086

[4] Hakimian, F., Farid, H., Ismail, M.N. and Nair, P.K. (2016) Importance of Commitment in Encouraging Employees' Innovative Behaviour. Asia-Pacific Journal of Business Administration, 8, 70-83. https://doi.org/10.1108/APJBA-06-2015-0054

[5] Li, M., and Hsu, C.C.H. (2016) A Review of Employee Innovative Behavior in Services. International Journal of Contemporary Hospitality Management, 28, 2820-2841. https://doi.org/10.1108/IJCHM-04-2015-0214

[6] Rhoades, L. and Eisenberger, R. (2002) Perceived Organizational Support: A Review of the Literature. Journal of Applied Psychology, 87, 698-714. https://doi.org/10.1037//0021-9010.87.4.698

[7] Cureton, S.S. (2014) The Role of Exchange Ideology in Coworker Social Support and Work Engagement. The University of Southern Mississippi, Hattiesburg, MS.

[8] Schaufeli, W.B. and Bakker, A.B. (2004) Job Demands, Job Resources, and Their Relationship with Burnout and Engagement: A Multi-Sample Study. Journal of Organizational Behavior. Journal of Organizational Behavior, 25, 293-315. 
https://doi.org/10.1002/job.248

[9] Caesens, G., Stinglhamber, F. and Luypaert, G. (2014) The Impact of Work Engagement and Workaholism on Well-Being: The Role of Work-Related Social Support. Career Development International, 19, 813-835.

https://doi.org/10.1108/CDI-09-2013-0114

[10] Saks, A.M. (2006) Antecedents and Consequences of Employee Engagement. Journal of Managerial Psychology, 21, 600-619. https://doi.org/10.1108/02683940610690169

[11] Karatepe, O.M. and Olugbade, O.A. (2009) The Effects of Job and Personal Resources on Hotel Employees' Work Engagement. International Journal of Hospitality Management, 28, 504-512. https://doi.org/10.1016/j.ijhm.2009.02.003

[12] Inoue, A., Kawakami, N., Tsuno, K., Shimazu, A., Tomioka, K. and Nakanishi, M. (2013) Job Demands, Job Resources, and Work Engagement of Japanese Employees: A Prospective Cohort Study. International Archives of Occupational and Environmental Health, 86, 441-449. https://doi.org/10.1007/s00420-012-0777-1

[13] Simbula, S. (2010) Daily Fluctuations in Teachers' Well-Being: A Diary Study Using the Job Demands-Resources Model. Anxiety, Stress, \& Coping, 23, 563-584. https://doi.org/10.1080/10615801003728273

[14] Jose, G. and Mampilly, S.R. (2015) Relationships among Perceived Supervisor Support, Psychological Empowerment and Employee Engagement in Indian Workplaces. Journal of Workplace Behavioral Health, 30, 231-250. https://doi.org/10.1080/15555240.2015.1047498

[15] Seibert, S.E., Wang, G. and Courtright, S.H. (2011) Antecedents and Consequences of Psychological and Team Empowerment in Organizations: A Meta-Analytic Review. Journal of Applied Psychology, 96, 981-1003. https://doi.org/10.1037/a0022676

[16] Quiñones, M., Van den Broeck, A. and De Witte, H. (2013) Do Job Resources Affect Work Engagement via Psychological Empowerment? A Mediation Analysis. Journal of Work and Organizational Psychology, 29, 127-134. https://doi.org/10.5093/tr2013a18

[17] Dagher, G.K., Chapa, O. and Junaid, N. (2015) The Historical Evolution of Employee Engagement and Self-Efficacy Constructs: An Empirical Examination in a Non-Western Country. Journal of Management History, 21, 232-256. https://doi.org/10.1108/JMH-05-2014-0116

[18] Susan, A. (2012) Job Satisfaction as an Antecedent to Employee Engagement. SIES Journal of Management, 8, 27-36.

[19] Takawira, N., Coetzee, M. and Schreuder, D. (2014) Job Embeddedness, Work Engagement and Turnover Intention of Staff in a Higher Education Institution: An Exploratory Study. SA Journal of Human Resource Management, 12, 1-10. https://doi.org/10.4102/sajhrm.v12i1.524

[20] Haddon, H., Shukrallah, S., Adel, M., Al-Tawy, A., Rashwan, N. and Ali, R. (2013) Live Updates: Morsi Ousted; Head of Constitutional Court to Take over Egypt Presidency. Ahram Online. 